\title{
Preparation and Characterization of Electrolessly Deposited Platinum and Palladium Nanoparticles on Pyrolyzed Photoresist Films on Silicon Substrates
}

\author{
Vivian L. Liang, Raymond Chan and Oliver Chyan ${ }^{\dagger}$ \\ Department of Chemistry \\ University of North Texas \\ Denton, Texas 76203 USA
}

Received February 28, 2002 Accepted March 14, 2002

\begin{abstract}
The effects of metal depositions on pyrolyzed photoresist films (PPF) grown on silicon substrates were investigated. A silicon chip, spin-coated with a positive photoresist was pyrolyzed through heating to form a PPF, or a conductive carbon film. For increasing periods of time, nanometersized metal particles of platinum and palladium were spontaneously deposited on conductive carbon films by immersion in solutions of $0.049 \%$ HF containing 100 ppm, 200 ppm, and 500 ppm concentrations of metal ions $\mathrm{Pt}^{2+}$ or $\mathrm{Pd}^{2+}$. Following each hour of deposition, the electrochemical behavior of the metal-deposited carbon films were investigated by cyclic voltammetry, utilizing a $0.1 \mathrm{M} \mathrm{H}_{2} \mathrm{SO}_{4}$ electrolyte system. The electron-transfer rates and characteristics of hydrogen evolution exhibited positive catalytic effects when the platinum and palladium nanoparticles were deposited on the carbon films. Scanning electron microscopy and energy-dispersive $\mathrm{x}$-ray analysis were employed to characterize the surface morphology and distribution of metal nanoparticles on the PPF surface based on metal ion concentration and deposition time. The depositions of metal nanoparticles accelerate the electron transfer process, which could improve the efficiency and performance of PPF electrodes in the production of hydrogen fuel.
\end{abstract}

\section{INTRODUCTION}

The significant relationships between the surface structure and the electrochemistry of carbon electrodes have long been studied [1-6]. Several types of carbon surfaces, such as glassy carbon $[7,8]$, carbon matrix electrodes [9], and activated carbon [10], have been used for deposition of metals [11,12]. Increased knowledge in this area continually enhances the performance of carbon electrodes and expands their use in industrial applications [13-18], such as in electrochemistry and in micro-electromechanical systems (MEMS) for batteries, capacitors, sensors, and other devices in the semiconductor industry. One type of carbon electrode involves photoresists (organic-based materials that are light-reactive and crucial to the manufacture of integrated circuit technology), which can be easily adapted to produce electrodes with complex geometry through patterning by photolithography techniques. Uniform photoresist films provide a reliable carbon source when pyrolysis transforms the organic coatings into conductive carbon films [11-17]. While previous research has established that the structural roles of those carbon electrode surfaces relate to the electron transfer kinetics of such surfaces [5,6,18-26], existing knowledge on the effects of metal nanoparticle depositions on carbon films is

${ }^{\dagger}$ To whom correspondence should be sent 
scarce. In this paper, we report a new approach of depositing metal nanoparticles on the PPF film through a solution only route. The effects of platinum and palladium metal nanoparticles on the electrochemical properties on pyrolyzed photoresist films were investigated. Electrochemical techniques and scanning electron microscope were utilized to observe the electron transfer kinetics and surface morphologies of the metal-deposited PPF formed on silicon substrates. These studies evaluated the notion that the metal nanoparticles deposited on the carbon films would produce faster electron transfer kinetics.

\section{EXPERIMENTAL}

Testing the effects of metal nanoparticles on PPF involved processes in the electrode preparation (Figure 1), as well as processes in electrochemistry (Figure 2) and in surface chemistry.

An n-type (111) silicon wafer was cut into $1.0 \times 2.0 \mathrm{~cm}^{2}$ pieces. The silicon substrates, cleaned and treated with $4.9 \%$ HF (Hashimoto) for hydrogen termination, were spin-coated with an AX P4330-RS photoresist (Clariant) at $3000 \mathrm{rpm}$ for 10 seconds at a time. Each substrate was spincoated four times for a uniform thickness. The chips were set in a specially made quartz tube, which was then placed in a tube furnace for heating in a reducing atmosphere, created by a constant flow of forming gas $\left(90 \% \mathrm{~N}_{2}, 10 \% \mathrm{H}_{2}\right)$ that moved through the tube. The high temperatures of the tube furnace allowed the spin-coated photoresist/silicon chips to pyrolyze. The temperature in the tube furnace increased at a rate of $50^{\circ} \mathrm{C}$ per minute from room temperature to $90^{\circ} \mathrm{C}$ and sustained for 30 minutes. The temperature of oven was then increased to $300^{\circ} \mathrm{C}$ and remained at $300^{\circ} \mathrm{C}$ for 30 minutes.

Finally, the temperature increased to $1000^{\circ} \mathrm{C}$ and sustained for one hour before it decreased back down to room temperature. Once heated, a PPF formed on the silicon, thus creating a uniform carbon film on the surface of the silicon chip. Metal nanoparticles were deposited on PPF through electroless deposition [27-29]. To achieve that outcome, deposition took place when the carbon film was submerged, for a

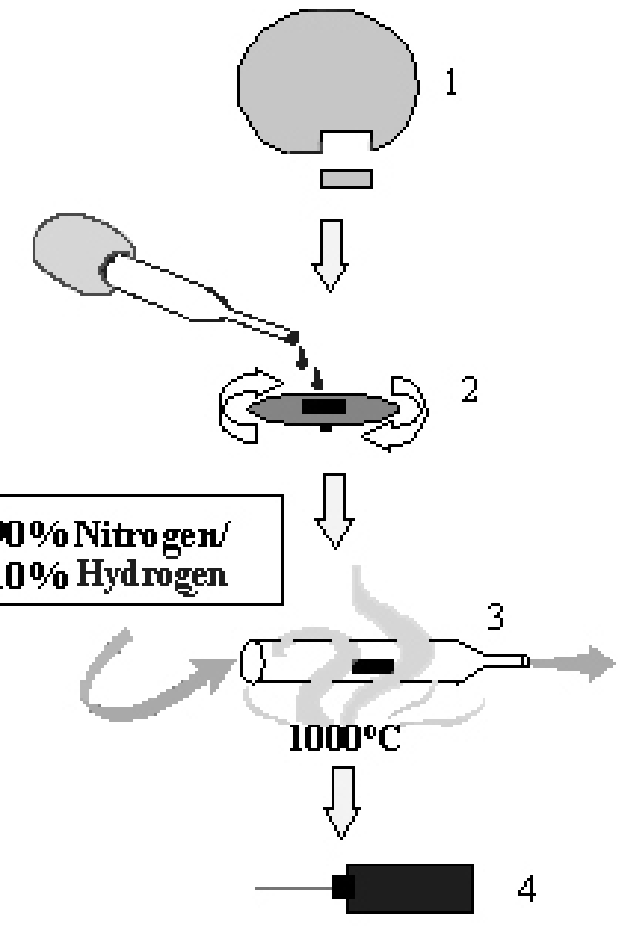

Figure 1. Procedures for Preparing PPF on Si. 1) A silicon wafer is cut into chips. Chips are cleaned and treated with HF for hydrogen termination. 2) Each chip is spincoated four times for a uniform thickness. 3) Chips heat up in a tube furnace under a reducing atmosphere in order to pyrolyze. 4) A conductive carbon film has formed, and the chip is ready for use as an electrode in electrochemical experiments.

deposition time of one hour, to an acidic solution of $0.049 \%$ hydrofluoric acid (HF) containing metal ions of either platinum $\left(\mathrm{Pt}^{2+}\right)$ or palladium $\left(\mathrm{Pd}^{2+}\right)$; the same deposition was then carried out for a second and third hour individually. After each hour of those depositions, the carbon film was removed from the solution and changes in surface structure/morphology and electrochemical behavior were investigated. This procedure was executed for chips deposited

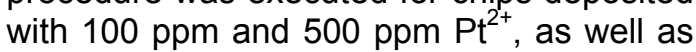
for depositions with $100 \mathrm{ppm}$ and $500 \mathrm{ppm}$ $\mathrm{Pd}^{2+}$, in a solution with $0.049 \% \mathrm{HF}$.

The electrochemical characterization, mainly cyclic voltammetry (CV), of prepared electrodes was carried out in a 0.1 $M$ sulfuric acid $\left(\mathrm{H}_{2} \mathrm{SO}_{4}\right)$ system using a EG\&G Model M273 Potentiostat/ 
Galvanostat. Experimentation with CV involves an electrochemical cell, Figure 2, that contains the following: a PPF on silicon working electrode, a $\mathrm{Ag} / \mathrm{AgCl}$ reference electrode, and a platinum counter electrode. These three electrodes, immersed in the $\mathrm{H}_{2} \mathrm{SO}_{4}$ solution, provide a basis for electrochemical measurements. CV generally traces the transfer of electrons in an oxidation-reduction (redox) reaction and characterizes redox reactions by exhibiting the measured current as a function of applied potentials, thus contributing to the analysis of electron transfer kinetics of electrodes. For each experiment, the CV was scanned forward for the oxidation reaction and scanned back to the starting point for the reduction reaction, cycling three times at a rate of 200 millivolts per second.

To establish the qualitative effects the depositions had on PPF, the characteristic appearance of the carbon surfaces deposited with metals was examined. The metal-deposited PPF surfaces were analyzed by using scanning electron microscopy (SEM) and energydispersive X-ray analysis (EDX). Surface morphologies and the nanometer-sized metal deposits were observed under SEM. EDX confirmed the deposition and dispersion of particles for different surfaces. The dispersion and magnitude of nanoparticles deposited on PPF films depended on the type of metal deposited, the concentration of the metal ions, and the deposition time. The study of the films on the microscopic level presented a better understanding of the metal deposits on the carbon surface.

\section{RESULTS AND DISCUSSION}

The results of the electrochemical experimentation and surface characterization data of the metal-deposited PPF on silicon revealed a catalytic effect on the electron transfer process, as well as an enhanced understanding of the surface structure. Several trials were performed with different samples of PPF deposited with platinum $(\mathrm{Pt})$ and palladium $(\mathrm{Pd})$ of various concentrations and time periods.

For both metals, CV data (as represented in Figure 3) generally exhibited that the cathodic current of hydrogen evolution progressively increased as the

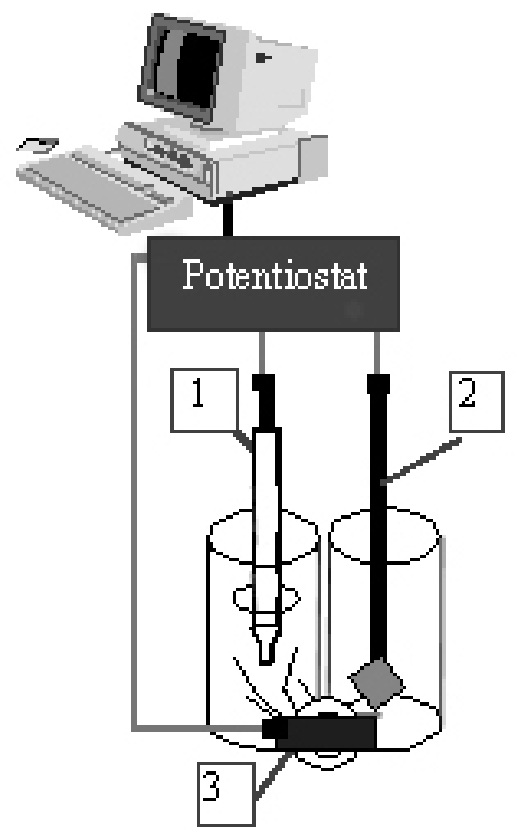

Figure 2: Electrochemistry Setup Experimentation with cyclic voltammetry involved a $0.1 \mathrm{M}$ sulfuric acid system and an electrochemical cell that contained the following: 1) a $\mathrm{Ag} / \mathrm{AgCl}$ reference electrode; 2) a platinum counter electrode; 3) a PPF on silicon working electrode.

amounts of metal nanoparticles increased on the film signifying a faster electron transfer rate. The increase in hydrogen evolution with the progression of deposition time can be observed from the changes in the current at the switching potentials. The faster electron transfer kinetics illustrate that the depositions of metal nanoparticles catalytically enhance electrochemical re-actions on the carbon films.

The qualitative data from SEM imaging verified depositions of metals on the PPF on silicon. Overall, results of the surface characterization demonstrated that the increases in deposition time, as well as metal concentration, increased the amount of metal deposits on the carbon film. The success of the electroless metal deposition is due largely due to the metal inducedoxidation of the silicon substrate [27-29].

For the $100 \mathrm{ppm}$ Pt (Figure 4) we see that there has been deposition of $\mathrm{Pt}$ metal with both larger and smaller clusters of the metal on the PPF surface after one hour deposition time. After three hours, the 


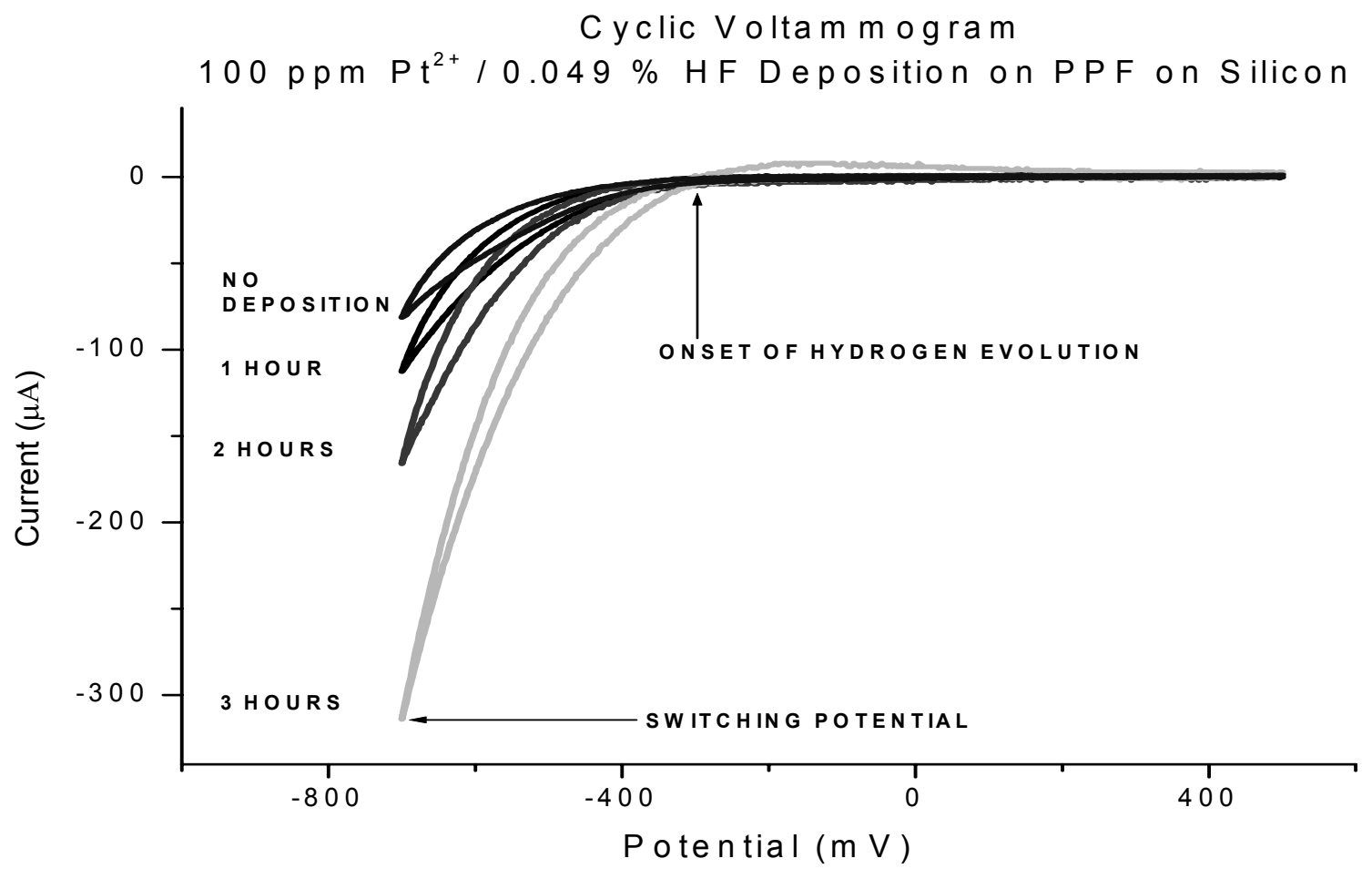

Figure 3. The representative graphs of $\mathrm{CV}$ in a sulfuric acid system exhibit an increase in hydrogen gas evolution concurrent with an increase in deposition time. Overall, data signifies that the depositions of metal nanoparticles catalyze the electron transfer kinetics of the carbon electrode.

larger Pt clusters have fallen away, presumably under its own weight while the smaller clusters have grown in number. 500 ppm $\mathrm{Pt}$ deposition (Figure 5) show an increase in the amount of metal clusters depositing on the PPF surface from one to three hours, with an emphasis on the fact that these clusters are much more uniform in size. In both $\mathrm{Pt}$ deposition concentrations, CV data corroborates the SEM observations by showing a progressive increase in cathodic current with an increase in deposition concentration and time.

Deposition with $100 \mathrm{ppm} \mathrm{Pd}$ at 1 hour (Figure 6) shows a very sparse deposition of $\mathrm{Pd}$ particles, but increase in both size and number after a three hour deposition time. 500 ppm deposition of $\mathrm{Pd}$ (Figure 7) show an increase in number and size of clusters forming from the one hour to the three hour, but with a number of larger gaps forming between clusters. CV data for
$500 \mathrm{ppm} \mathrm{Pd}$ is in agreement with the observation that the third hour of deposition tends to be out of line with expectations (i.e., the current at the switching potential should be greater,) formed from the results of the first and second hours of deposition for Pd. One possible explanation for this phenomenon is that increased deposition time may affect the carbon films, such that the amount of metal deposited surpasses the capabilities of the carbon film to accumulate any additional particles. Another explanation may be the fact that increased exposure of the PPF to HF solutions may be detrimental to the carbon surface or carbon/silicon interface. It is also possible that the formation of $\mathrm{Pd}$ clusters at $500 \mathrm{ppm} \mathrm{Pd}$ occurs at such a high rate that the metal clusters are unable to physically stay on the surface due to its own mass, falling off the substrate and forming the gaps, which are observed [27]. 

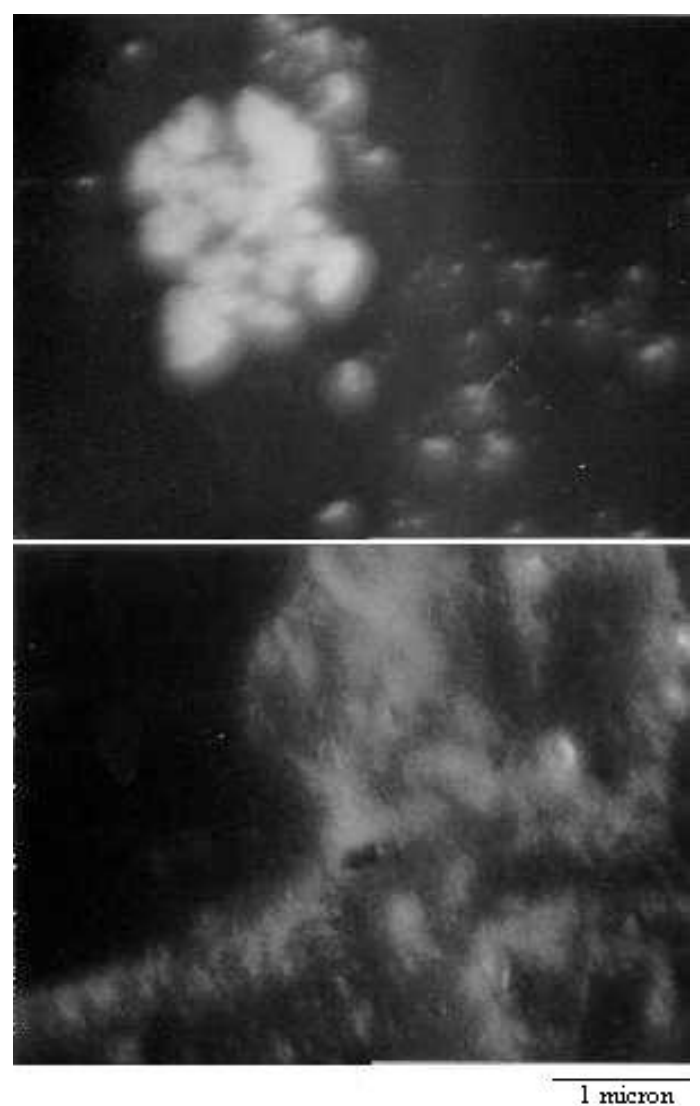

Figure 4. SEM image of 100 ppm $\mathrm{Pt}^{2+} / 0.049 \% \mathrm{HF}$ deposited on PPF on silicon at a magnification of 2000x. The top figure illustrates the surface after 1 hour of deposition; the bottom figure illustrates the surface after 3 hours of deposition.

\section{SUMMARY}

This research endeavor provides useful information on the preparation and characterization of a new type of pyrolyzed photoresist films modified with the $\mathrm{Pt}$ and $\mathrm{Pd}$ nanoparticles. The beneficial electrocatalytic effect of the metal deposition was confirmed by the increase of the hydrogen evolution current density that took place at a more positive on-set potential. The surface characterization data obtained by the SEM and EDX collaborated well with the finding from electrochemical investigation. This project has laid the preliminary groundwork for the future studies on metal nanoparticles deposition on carbon films that could find useful applications in fuel-cell, battery and electrochemical sensors.
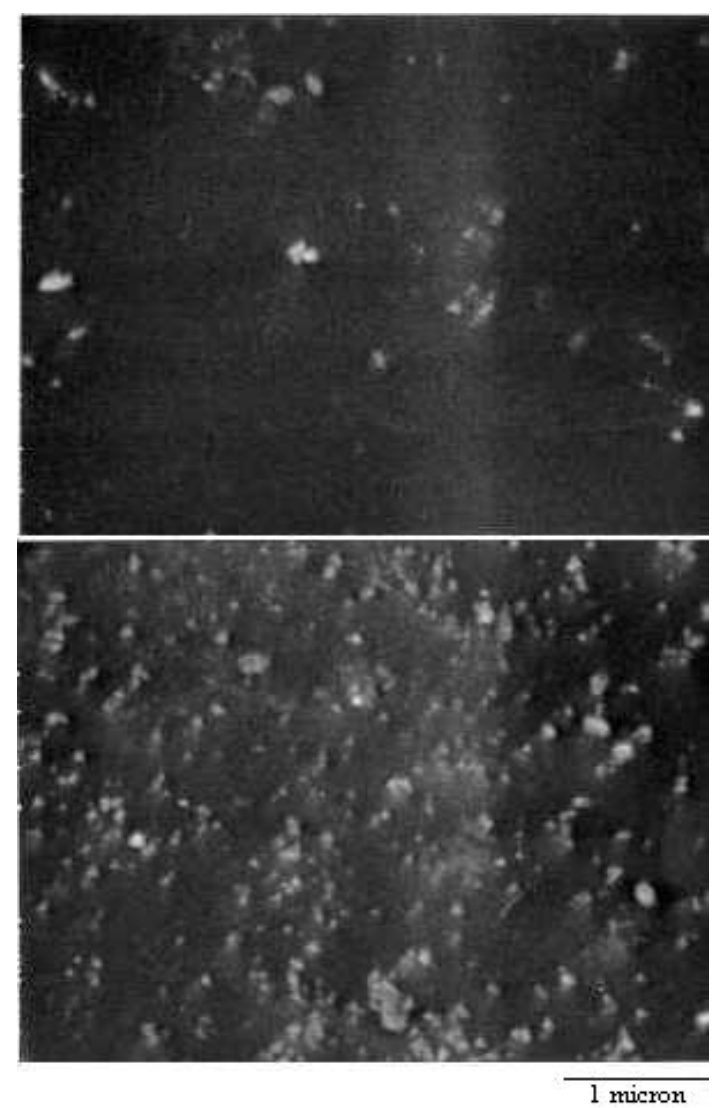

Figure 5. SEM image of 500 ppm $\mathrm{Pt}^{2+} / 0.049 \% \mathrm{HF}$ deposited on PPF on silicon at a magnification of $2000 x$. The top figure illustrates the surface after 1 hour of deposition; the bottom figure illustrates the surface after 3 hours of deposition.

\section{ACKNOWLEDGEMENTS}

The authors gratefully acknowledge the Robert A. Welch Foundation for financial support of this work. We also thank Texas Instruments for a generous gift of silicon wafers. V. Liang gratefully acknowledges a summer research scholarship from the Texas Academy of Mathematics and Science (TAMS) at UNT.

\section{REFERENCES}

1. Gaylor, V.F.; Elving, P.J.; Conrad, A.L.; Anal. Chem. 25, 1078 (1953).

2. Cabanis, G.E.; Hu, I.F.; Karweick, D.H.; Kuwana, T.; J. Electroanal. Chem. 188, 59 (1985).

3. Diamantis, A.A.; Murphy Jr., W.R.; Linton, R.W.; Meyer, T.J.; J. Am. Chem. Soc. 107, 1845 (1985). 


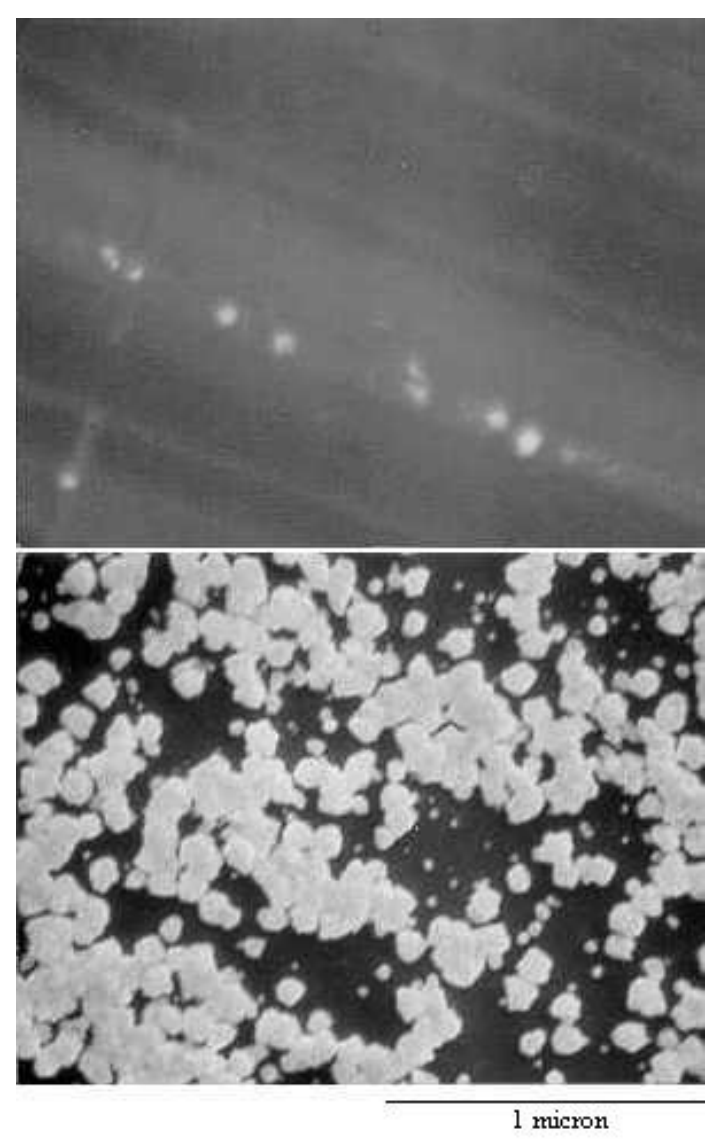

Figure 6. SEM image of 100 ppm $\mathrm{Pd}^{2+} / 0.049 \%$ HF deposited on PPF on silicon at a magnification of 5000x. The top figure illustrates the surface after 1 hour of deposition; the bottom figure illustrates the surface after 3 hours of deposition.

4. Anjo, D.M.; Karh, M.; Khodabaksh, M.M.; Nowinski, S.; Wanger, M. Anal.Chem., 61, 2603 (1989).

5. Chen, P.; McCreery, R. Anal. Chem., 68, 3958 (1996).

6. Kuo, T-C.; McCreery, R. Anal. Chem., 71, 1553 (1999).

7. Sherstyuk, O. V; Pron'kin, S.N.; Chuvilin, A. L.; Salanov, A.N.; Savinova, E. R.; Tsirlina, G.A.; Petrii, O.A. Russ. J. Electrochem., 36, 741 (2000).

8. CoX, J.A.; Tess, M.E.; Cummings, T.E.; Rev. Anal. Chem. 15, 173 (1996).

9. Lee, S-B; Pyun, S-I. J. Appl. Electrochem. 30, 795 (2000).

10. Gurrath, M; Kuretzky, T.; Boehm, H.P.; Okhlopkova, L.B.; Lisitsyn, A.S.; Likholobov, V.A. Carbon. 38, 1241 (2000).

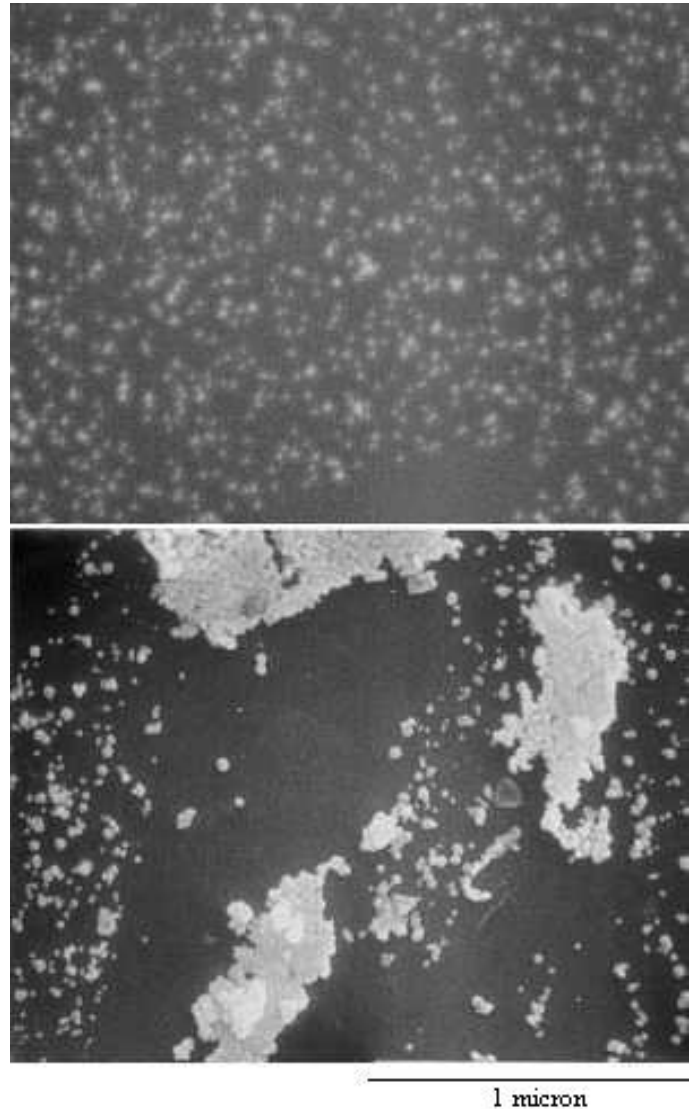

Figure 7. SEM image of 500 ppm $\mathrm{Pd}^{2+} / 0.049 \% \mathrm{HF}$ deposited on PPF on silicon at a magnification of $5000 x$. The top figure illustrates the surface after 1 hour of deposition; the bottom figure illustrates the surface after 3 hours of deposition.

11. Liu, S.; Tang, Z.; Wang, E.; Dong, S. Electrochem. Commun. 2, 800 (2000).

12. Ozaki, J.; Ohizumi, W.; Oya, A.; IllanGomez, M.J.; Raman-Marrtinez, M.C.; Linares-Solano, A.; Carbon, 55, 125 (2000).

13. Jenkins, G.; Kawamura, K. Polymeric Carbons-Carbon Fibre, Glass and Char (p.15) Cambridge University Press. Cambridge England, 1976.

14. Kim, J.; Song, X.; Kinoshita, K.; Madou, M.; White, R. J. Electrochem. Soc., 145, 2314 (1998).

15. Kostecki, R.; Song, X.; Kinoshita, K. Electrochem. Solid-State Lett., 2, 465 (1999).

16. Ranganathan, S.; McCreery, R.; Majji, S. M.; Madou, M. J. Electrochem. Soc., 147, 277 (2000). 
17. McCreery, R.; Ranganathan, S. Anal. Chem., 73, 893 (2001).

18. Makkee, M.; Wiersma, A.; can de Sandant, E.J.A.X.; van Bekkum, H.; Moulijn, J.A.; Catalysis Today, 55, 125 (2000).

19. Cabaniss, G.; Diamantis, A.; Murphy, W.; Linton, R.; Meyer, T. J. Am. Chem. Soc., 107, 1845 (1985).

20. Yang, H-H.; McCreery, R. Anal. Chem., 71, 4081 (1999).

21. Wang, J.; Chen, W.; Renshever, C.C.; White, C.; Anal. Chem., 66, 1988 (1994).

22. Duvall, S.; McCreery, R. Anal. Chem. 71, 4594 (1999).

23. Renschler, C.L.; Sylvester, A.P.; Salgado, J.; Mater. Res. 4, 452 (1989).

24. Liu, Y-C.; McCreery, R. Anal. Chem. 69, 2091 (1997).

25. Sheuller, O.J.A.; Brittain, S.T.; Whitesides, G.M. Chem. Matter. 9, 1399 (1997).

26. Ray, K.; McCreery, R. Anal. Chem. 69, 4680 (1997).

27. Gao, J-S.; Arunagiri, T.; Chen, J-J.; Goodwill, P.; Chyan, O. Chem. Mater. 12, 3495-3500 (2000).

28. Chyan, O.M.R.; Chen, J-J.; Chien, H-Y.; $\mathrm{Wu}, \mathrm{J} . ;$ Liu, M. J. Electrochem. Soc. 143, L235 (1996).

29. Chyan, O.M.R.; Chen, J-J.; Chen, L.; Xu, F. J. Electrochem. Soc. L17 (1997). 
